\title{
Who is utilizing anti-retroviral therapy in Ghana: An analysis of ART service utilization
}

\author{
Phyllis Dako-Gyeke ${ }^{1 *}$, Rachel Snow ${ }^{2}$ and Alfred E Yawson ${ }^{3,4}$
}

\begin{abstract}
Introduction: The global scale-up of antiretroviral therapy (ART) for HIV patients has led to concerns regarding inequities in utilization of ART services in resource-limited contexts. In this paper, we describe regional and sex differentials in the distribution of ART among adult HIV patients in Ghana. We highlight the need for interventions to address the gender-based and geographic inequities related to the utilization of ART services in Ghana.

Methods: We reviewed National AIDS/STIs Control Program's ART service provision records from January 2003 through December 2010, extracting data on adults aged 15+ who initiated ART in Ghana over a period of eight years. Data on the number of patients on treatment, year of enrollment, sex, and region were obtained and compared.

Results: The number of HIV patients receiving ART in Ghana increased more than 200-fold from 197 in 2003, to over 45,000 in 2010. However, for each of six continuous years (2005-2010) males comprised approximately one-third of adults newly enrolled on ART. As ART coverage has expanded in Ghana, the proportion of males receiving ART declined from $41.7 \%$ in 2004 to $30.1 \%$ in 2008 and to $27.6 \%$ in 2010. Also, there is disproportionate regional ART utilization across the country. Some regions report ART enrollment lower than their percent share of number of HIV infected persons in the country.

Conclusions: Attention to the comparatively fewer males initiating ART, as well as disproportionate regional ART utilization is urgently needed. All forms of gender-based inequities in relation to HIV care must be addressed in order for Ghana to realize successful outcomes at the population level. Policy makers in Ghana and elsewhere need to understand how gender-based health inequities in relation to HIV care affect both men and women and begin to design appropriate interventions.
\end{abstract}

Keywords: Inequities, ART, Utilization, Sex, Regional, Ghana, HIV and AIDS

\section{Introduction}

The global expansion of antiretroviral therapy (ART) for HIV patients has raised concerns regarding inequities in utilization of ART services within countries [1-4]. The Global Fund, PEPFAR, WHOs " 3 by 5 " initiative, and efforts by other public and private organizations have ensured the scale-up of ART in resource-constrained settings over the last 8 years [5-8]. In 2010 it was estimated that approximately 6.6 million people in low- and middle-income countries were receiving HIV treatment,

\footnotetext{
* Correspondence: gyekenay@yahoo.com

'Department of Social and Behavioral Sciences, School of Public Health, College of Health Sciences, University of Ghana, P. O. Box LG 13, Accra, Ghana

Full list of author information is available at the end of the article
}

representing approximately $47 \%$ of people who needed treatment [9]. In Ghana, a total of 33,745 people were receiving ART by the end of 2009 [10]. The availability of ART has transformed what was once a deadly disease into a manageable chronic condition [1]. However due to geographical and gender-based health inequities related to HIV treatment, not all patients in need of ART in resource-limited settings utilize the service.

Inherent challenges such as limited institutional, financial, and human resources can cause geographic disparities in utilization of ART within resource-limited contexts [11,12]. Additionally, gender-based inequities have been increasingly identified with HIV-related care and treatment, as well as general health care utilization $[13,14]$. Theoretical work on why males and females

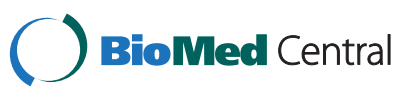


differ in health seeking behavior has seen extensive, if not decisive, treatment in the global health and sociological literature [15-18]. This literature suggests that gender inequities, norms and attitudes may work differently in different contexts to hinder either men or women from accessing HIV treatment [13,14,19-22]. Even though women are often more susceptible to HIV infection than men [23], their access to HIV treatment can be constrained by limits on their mobility, limited control over household resources, poverty, lack of health insurance, social support, or fear of stigma [13,21-25]. Although men's utilization of ART can be inhibited for similar reasons, [26-28] compelling arguments have been made that hegemonic masculinities across many cultures include demands that men under-attend to potential physical weaknesses $[16,17,29]$. Consequently, men are keen to identify as 'not feminine', which includes avoiding frequent and trivial use of health services [18]. We would argue that such anxieties may be augmented for the diagnosis and treatment of HIV or other potential sexual infections, in which the patient-provider interaction must inevitability focus on issues of sexual illhealth, and potential fears of sexual disempowerment.

Several sex disaggregated analyses conducted in various parts of Africa show either high proportions of females receiving ART in some countries (South Africa, Botswana, Ethiopia, Ivory Coast, Malawi, and Zimbabwe) $[13,14,30-32]$ or high male utilization of ART in others (Swaziland, and Zambia) [14]. Advancing equity in health means addressing gender-based and geographical disparities associated with the utilization of ART services across Africa.

In Ghana, the HIV population is estimated at approximately 221,941 [33], and the HIV virus has spread to all ten administrative regions in the country. ART services have been available to HIV patients since June 2003; guidelines from the National AIDS/STIs Control Program (NACP) recommend patients to initiate treatment when their CD4 count is less than 350 cells $/ \mathrm{ml}$ and/or they become symptomatic with HIV infection in WHO stage III or IV [34]. Although there has been an increase in the number of patients receiving ART, approximately $70 \%$ of the HIV- infected population in Ghana is not on treatment $[35,36]$. UNAIDS identified Ghana as one of 11 countries with less than $40 \%$ ART coverage in 2009 [36]. To help address this problem, the Ghanaian government is currently making efforts to increase coverage to $60 \%$ of those eligible for treatment by 2013 [10]. To inform the further scale up of ART services, we undertook a review of patients receiving ART in the country. Both the regional and sex distribution of patients receiving ART, especially when cost of ART no longer seems to be a constraint, are highlighted.
Rigorous examination of current ART programs in resource-limited settings is critical to identify implementation gaps and to suggest context-specific interventions that can improve accessibility for all eligible HIV patients $[1,37]$. It is imperative to address inequities regarding access and utilization of ART, ensuring wide spread and timely access, as well as prolonged healthy living among HIV patients [6]. Prolonged healthy living helps HIV response efforts at the population level by reducing stigma, promoting prevention-oriented behavior and thereby reducing the further spread of the virus [9]. To document the regional and sex disparities, this study reviews NACP dataset $[10,38]$.

\section{Methods}

The data source for this review is NACP sex and region disaggregated records on adults aged $15+$ who initiated ART from 2003 to 2010. The NACP is responsible for coordination and implementation of HIV and AIDSrelated aspects of the Ghana Health Strategic Framework. Implementation is managed by the Disease Control and Prevention Department of the Public Health Directorate of the Ghana Health Service. NACP sources and collates computerized HIV and AIDS- related service provision data from community health centers, district hospitals, regional hospitals and teaching hospitals throughout the country, every quarter. From these records, NACP generates a comprehensive national dataset that covers service provision across all ten administrative regions in Ghana. These data were the source for the 2010 Ghana's Progress Report on the United Nations General Assembly Special Session [10].

National and regional HIV prevalence for adults aged 15-49 years are estimated by NACP from antenatal and STI surveillance data, using recommended United Nations' algorithms [39]. Regional adult population figures provided in Table 1 were generated using the United States Census Bureau's 2010 estimation that $52 \%$ of the Ghanaian population is aged between 15-49 years [40]; this was applied to the 2010 Ghana population and housing census data for each region [41]. In order to determine who is utilizing ART, the sex of adult HIV patients receiving ART in each year (2003-2010) are displayed. Also, trends are examined by comparing new ART enrollments (sex and total) over time. In addition, a detailed analysis of the geographic (regional) location of patients receiving treatment in the year 2010 is provided by contrasting the proportion of the total Ghanaian population residing in each region with the proportion of the total HIV + population, and the ARTusing population in that region; discrepancies are noted. Descriptive statistics include simple frequencies, proportions, percentages and ratios. These are presented by year of enrollment, sex and region. All analyses were 
Table 1 Regional Distribution of HIV Patients on ART

\begin{tabular}{|c|c|c|c|c|c|c|}
\hline \multicolumn{7}{|c|}{ Regional Distribution of HIV Patients Enrolled on ART, By Population Distribution \& HIV Prevalence (2010) } \\
\hline Region & $\begin{array}{l}\text { Adult Population } \\
\text { Share }^{\mathrm{a}}\end{array}$ & $\begin{array}{l}\text { Adult HIV } \\
\text { Prevalence, } \\
2010^{\mathrm{b}}\end{array}$ & $\begin{array}{l}\text { Number of Adults } \\
\text { Infected }^{c}\end{array}$ & $\begin{array}{l}\text { Regional Share } \\
\text { of Ghana's } \\
\text { Infected Adults }\end{array}$ & $\begin{array}{l}\text { Number Started } \\
\text { on ART, } 2010\end{array}$ & $\begin{array}{l}\text { Regional Share of Adults } \\
\text { who Initiated ART } \\
\text { in Ghana, in } 2010\end{array}$ \\
\hline Ashanti & $19.5 \%(2457024)$ & $3.0 \%$ & 73711 & $25.4 \%$ & 2395 & $20.2 \%$ \\
\hline Eastern & $10.7 \%(1349927)$ & $3.2 \%$ & 43198 & $14.9 \%$ & 2116 & $17.8 \%$ \\
\hline Greater Accra & $16.1 \%(2033077)$ & $2.6 \%$ & 52860 & $18.2 \%$ & 1952 & $16.5 \%$ \\
\hline Brong Ahafo & $9.4 \%$ (1186707) & $2.0 \%$ & 23734 & $8.2 \%$ & 1432 & $12.1 \%$ \\
\hline Volta & $8.7 \%$ (1091936) & $1.8 \%$ & 19655 & $6.8 \%$ & 1118 & $9.4 \%$ \\
\hline Western & $9.6 \%(1209310)$ & $2.5 \%$ & 30233 & $10.4 \%$ & 1,048 & $8.8 \%$ \\
\hline Central & $8.7 \%$ (1095749) & $1.7 \%$ & 18628 & $6.4 \%$ & 609 & $5.1 \%$ \\
\hline Northern & $10.2 \%(1283650)$ & $0.7 \%$ & 8986 & $3.1 \%$ & 464 & $3.9 \%$ \\
\hline Upper West & $2.8 \%$ (352437) & $1.7 \%$ & 5991 & $2.1 \%$ & 347 & $2.9 \%$ \\
\hline Upper East & $4.3 \%$ (536369) & $2.4 \%$ & 12873 & $4.4 \%$ & $385^{* *}$ & $3.2 \%$ \\
\hline Total & $100 \%(12596184)$ & & 289868 & $100.0 \%$ & 11866 & $100.0 \%$ \\
\hline
\end{tabular}

** 2009 data for Upper East was used due to missing data for 2010.

${ }^{a}$ Adult population (15-49 years) share estimated as $52 \%$ of total population for each region. ${ }^{33,34}$

${ }^{b}$ Regional adult HIV prevalence. ${ }^{32}$

${ }^{c}$ Number infected is estimated using adult HIV prevalence and adult population share.

performed using the statistical software package SPSS version 19.

\section{Results}

\section{ART utilization trends in Ghana}

The data (Figure 1) show- high increases in the number of adults enrolled on ART from 2003 to 2004, and again from 2006 to 2007. When ART was initially rolled-out in 2003, 197 adults enrolled for the service. In the second year (2004) new enrollees increased to almost 2,000 adults, representing a $900 \%$ increase in one year. In 2007 a record 6,091 adults enrolled, an approximately two- fold increase in enrollments the previous year (Figure 1). By the end of 2010 the cumulative number of adults enrolled on ART in Ghana was approximately 45,000.

\section{Regional distribution of HIV patients on ART in Ghana}

Regional HIV prevalence rate in 2010 range from 3.2\% in the Eastern region to $0.7 \%$ in the Northern region (Table 1). With a 3.0\% HIV prevalence rate, Ashanti region contributed approximately $25.4 \%$ of the total number of HIV infected persons in Ghana, in the year 2010. Ashanti, Eastern and Greater Accra regions each accounted for a greater share in total HIV-positive cases in Ghana than

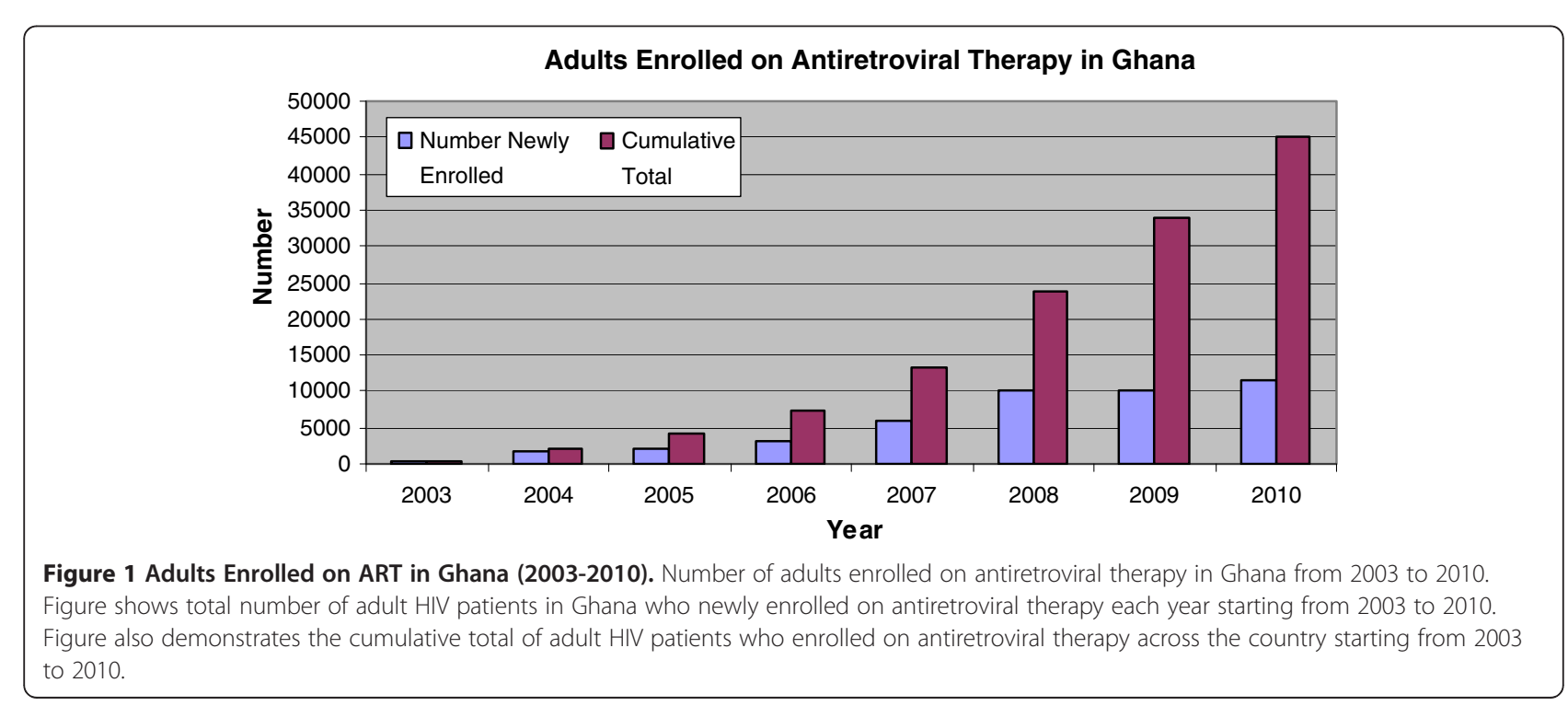


their share of the overall adult population in the country. This discrepancy was greatest in the Eastern region, which represents $10.7 \%$ of the adult Ghanaian population, but $14.9 \%$ (i.e. $39 \%$ more) of the adult HIV-positive cases in Ghana. The remaining seven regions of Ghana had proportions of HIV-positive cases that were either comparable or less than their share of the adult population.

The Ashanti region had the highest share of ART enrollees $(20.2 \%)$ in the year 2010 (Table 1), notably less than their $25 \%$ share of HIV-positive adults. Greater Accra also had proportionately more HIV-positive cases than they had enrollees on ART (Table 1). At the same time, the Eastern, Brong Ahafo and Volta regions had proportionately more adults using ART than their share of HIV-positive persons. Other regions where the percent share of overall ART enrollments was lower than the region's percent share of HIV infections included Western, Central and Upper East) regions (Table 1).

\section{Sex differentials in the distribution of patients on ART}

For the 8 year period within which ART services have been available in Ghana, more females than males have been enrolling (Table 2). In 2003 43.1\% of adults enrolled on ART were males, and this proportion declined precipitously in the following years, progressing to $41.3 \%$ in 2004, to $30.1 \%$ in 2008 and $27.6 \%$ in 2010 (Table 2). The F:M ratio was 1.3 in 2003, but steadily increased over the years (Figure 2).

\section{Sex distribution of HIV patients on ART in the ten regions of Ghana}

In the most recent year of data (2010), the F:M ratio in all ten regions was above 2.0 (Table 3 ). The Central region recorded the highest F:M ratio (3.4), followed by three regions (Brong Ahafo, Volta, and Upper East) each recording 2.9 F:M ratio in 2010 (Table 3). The lowest F:

\section{Table 2 Proportion of Females and Males on ART}

\begin{tabular}{|c|c|c|c|c|c|}
\hline \multicolumn{6}{|c|}{$\begin{array}{l}\text { Proportion of Females and Males Enrolled on ART From } \\
2003-2010\end{array}$} \\
\hline \multirow[t]{2}{*}{ Year } & \multirow{2}{*}{$\begin{array}{l}\text { Total Number } \\
\text { of Patients } \\
\text { Enrolled }\end{array}$} & \multicolumn{2}{|l|}{ FEMALES } & \multicolumn{2}{|l|}{ MALES } \\
\hline & & $\begin{array}{l}\text { Number } \\
\text { Enrolled }\end{array}$ & Proportion & $\begin{array}{l}\text { Number } \\
\text { Enrolled }\end{array}$ & Proportion \\
\hline 2003 & 197 & 112 & 0.569 & 85 & 0.431 \\
\hline 2004 & 1831 & 1067 & 0.583 & 764 & 0.417 \\
\hline 2005 & 2032 & 1270 & 0.625 & 762 & 0.375 \\
\hline 2006 & 3278 & 2060 & 0.628 & 1218 & 0.372 \\
\hline 2007 & 6091 & 3911 & 0.642 & 2180 & 0.358 \\
\hline 2008 & 10185 & 7119 & 0.699 & 3066 & 0.301 \\
\hline 2009 & 10131 & 7027 & 0.694 & 3104 & 0.306 \\
\hline 2010 & 11481 & 8315 & 0.724 & 3166 & 0.276 \\
\hline
\end{tabular}

$M$ ratio of 2.4 was reported by Ashanti, Eastern and Upper West Regions (Table 3).

\section{Discussion}

Despite profound increases in ART utilization, lower proportions of males are obtaining ART services in Ghana. For each of the six recent years (2005-2010), males consisted of less than one third of adults who newly enrolled on ART each year. The proportion of males who newly enrolled declined from $41.7 \%$ in 2004 to $27.6 \%$ in 2010 . Our finding is consistent with Family Health International's report on pilot projects that initiated ART in Ghana, Kenya and Rwanda [42]. The FHI report indicates women comprised a majority (62\%) of ART patients in all three countries [42]. Also, several studies conducted in other parts of Africa (South Africa, Botswana, Ethiopia, Ivory Coast, Malawi, and Zimbabwe) indicate similar over-representation of women in persons receiving ART [13,14,30-32]. After conducting a systematic review, Muula and his colleagues found a F: $M$ ratio of patients receiving ART to be equal to, or greater than 1 , in all but 2 of 21 published studies in seven Southern African countries [14].

The over-representation of women receiving ART may partially reflect the sex proportions of the adult population infected with HIV in African countries [43]. For instance, the 2003 Ghana Demographic and Health Survey reports nearly $3 \%$ national HIV prevalence for women aged 15-49 years, but less than $2 \%$ for men aged 1559 years [44], suggesting an F:M ratio of 1.8 to 1 . Also, the Ghana NACP 2010 [33] HIV estimates suggest that the F: $M$ ratio of the HIV-positive population in Ghana is 1.3:1. Irrespective of the comparatively high HIV prevalence among females, the Ghana AIDS Commission claims that in 2009, 50\% of females who needed ART were accessing the service while only $39 \%$ of males who needed ART had access [10], suggesting a 1.2:1 F:M ratio.

Wagner and his colleagues argue that most people do not seek HIV testing and care until they are experiencing severe symptoms and thus have a more advanced disease stage [7]. This situation is more likely the case for males in Africa as studies indicate that men start treatment with more advanced stages of illness which negatively impacts their prognosis $[13,45]$. In investigating the relationship between patient's clinical stage and CD4 count in Ghana, Torpey and his colleagues observed that seeking testing and care at a later HIV stage, and with very low CD4 count jeopardizes treatment outcomes [46].

The underrepresentation of males in ART enrollment may be attributed to lower HIV testing among males compared to females. Several studies in sub-Saharan Africa suggest women test for HIV more than men $[44,47,48]$ and also start treatment at an earlier clinical 


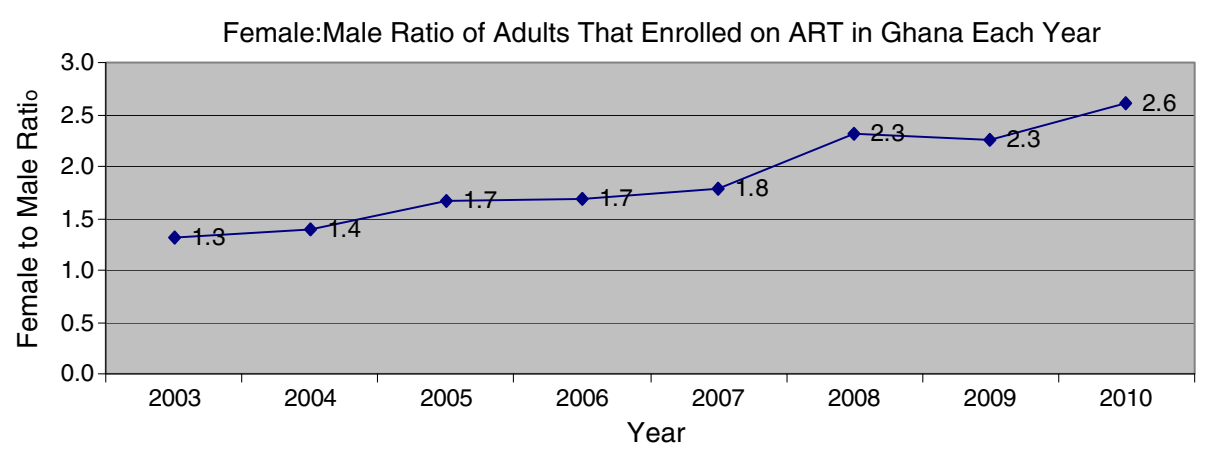

Figure 2 Female to Male Ratio of Adults Enrolled on ART in Ghana. Figure shows female to male ratio of adults enrolled on antiretroviral therapy in Ghana for each year, starting from 2003 to 2010. Figure shows the female to male ratio of total number of adult HIV patients in Ghana who newly enrolled on antiretroviral therapy each year starting from 2003 to 2010.

stage of HIV than men [13]. Since HIV testing serves as the funnel into HIV care and eventual ART initiation the underrepresentation of males in ART utilization in Ghana may simply be a direct consequence of the documented low HIV testing among men [7,44,47-49]. A recent four-year review (20072010) of HIV Testing and Counseling data from the NACP in Ghana found that F:M ratio of HIV testing ranged from 7.6 in 2007 to 4.2 in 2010 [49]. This finding was also confirmed by the 2008 Ghana Demographic and Health Survey which reported that women (17\%) were slightly more likely to have been tested for HIV and received their results than men (12\%) [48].

More structural and pragmatic explanations for male under-utilization of both HIV testing and ART enrollments are plausible, including the fact that women are generally more acculturated to the routine use of health services through child-bearing and responsibility for children's health. This may be particularly salient in

Table 3 Enrollment of Patients on ART

Enrollment of Patients on ART in All Regions in 2010 by Sex; Showing F: M Ratio

\begin{tabular}{llll}
\hline Region & $\begin{array}{l}\text { Total Number } \\
\text { Started on ART } \\
\text { in 2010 }\end{array}$ & $\begin{array}{l}\text { Number of Males } \\
\text { Started on ART } \\
\text { in 2010 }\end{array}$ & F:M Ratio \\
\hline Ashanti & 2395 & 702 & 2.4 \\
\hline Eastern & 2116 & 624 & 2.4 \\
\hline Greater Accra & 1952 & 536 & 2.6 \\
\hline Brong Ahafo & 1432 & 364 & 2.9 \\
\hline Volta & 1118 & 285 & 2.9 \\
\hline Western & 1048 & 286 & 2.7 \\
\hline Central & 609 & 138 & 3.4 \\
\hline Northern & 464 & 130 & 2.6 \\
\hline Upper West & 347 & 101 & 2.4 \\
\hline Upper East & $385^{* *}$ & 100 & 2.9 \\
\hline Total & 11866 & 3266 & 2.6 \\
\hline
\end{tabular}

** 2009 data for Upper East was used due to missing data for 2010.
African contexts where annual physical check-ups or health screening services are not yet routine for adult men or women. In this context, improvements in access to HIV testing among women attending antenatal care has been noted as a key entry point for women into HIV- related care [14]. In Ghana, HIV testing among pregnant women is encouraged as part of efforts to prevent mother to child transmissions.

Furthermore, researchers on masculinity and health generally attribute low male utilization of health care services to traditional concepts of masculinity that disassociate male identity from disease and project males as invulnerable and not needing health care $[16,17,29]$.

We would argue that such anxieties may be augmented for the diagnosis and treatment of HIV or other potential sexual infections, in which the patient-provider interaction must inevitability focus on issues of sexual ill-health, and potential fears of sexual disempowerment. That said, one should adopt western theories to the Ghanaian context with some degree of caution, given evidence of wide-ranging strategies for affirming dominant masculinity across social class, profession, or cultural location even within the USA or UK [50,51]. Instead, further investigation is warranted in the Ghanaian setting.

In addition to wide sex differentials, there is disproportionate ART use across the ten administrative regions in the country. Ashanti region, being the most populous region in the country, had the highest ART enrollments, followed by Greater Accra and Eastern regions. Considering that Accra, the capital of Ghana is located within the Greater Accra region, it is possible that the provision of ART in this region has become more feasible, partly due to the wide availability of health facilities within the urban sites of the region. Also the Eastern region which consistently records the highest HIV prevalence in the country continues to receive attention. Therefore, the high ART enrollment in the Eastern region may reflect 
interventions aimed at addressing the high HIV prevalence in that region.

Besides these three regions, other regions report ART enrollment that is either lower or higher than the region's percent share of number of HIV infected persons in the country. For instance, Brong Ahafo and Volta regions had comparatively high shares of ART enrollment, $12.1 \%$ and $9.4 \%$, respectively. These are more than their respective percent shares of number of HIV infected persons (Brong Ahafo, 8.2\%; Volta, 6.8\%). The regional utilization patterns demonstrate how scale-up efforts occurring simultaneously within different African settings may, or may not be necessarily responding to specific geographical needs [7]. For Ghana, these estimates highlight the regional differences in population HIV-burdens, and reflect the different coverage of ART for HIV-positive persons across Ghana.

Regardless of sex and regional differentials, there is an upward trend in ART utilization across the country. Although few HIV patients (197) enrolled when ART was initially piloted in June 2003 in Ghana, this effort laid the foundation for expansion of ART services in subsequent years. The records show over a two-hundred-fold increase in the number of HIV patients on ART across the country by the end of 2010. Similar increasing ART utilization trends were found in various resource-limited settings during this period $[12,52,53]$. One important factor that accounts for this steady increase in ART utilization in Ghana is the concurrent increase in the number of sites providing ART services. According to national reports, facilities providing ART services in Ghana increased from 3 in 2003, to 13 sites in 2005 [10]. By December 2009, this number had profoundly increased to 138. These are health facilities that provide ART for HIV patients at the district, regional and (Tertiary) national health facilities in both the public and private sector [10]. The enormous increase in number of adults enrolled on ART each year is indicative of numerous ART scale-up efforts initiated by public and private organizations across Africa including governments, non- government, and community-based organizations [7]. In Ghana, the scale-up has continued in the public sector with linkages to the private sector through the NACP [10].

Whereas the upward trend in ART utilization across the country provides evidence of the wide scale-up efforts, sex and regional disparities in utilization highlight HIV-related healthcare inequities that need to be further investigated and addressed. Although inherent challenges such as limited institutional resources and service capacity, may explain such gaps, the availability of a wide spectrum of alternative services for HIV patients in Ghana may explain why some HIV patients do not utilize ART services. Research conducted by Awusabo-Asare and Anarfi on the health-seeking behavior of persons with HIV and AIDS in Ghana indicate that, after being diagnosed, HIV patients in Ghana may also visit the traditional healer or spiritualist considering the supernatural explanations given to HIV infection in some cases [54]. Also, other studies suggest the possibility of HIV patients seeking care through the informal sector [13]. Preference for the informal sector may be due to fear of stigma and disclosure of HIV status, perception that hospitals are unfriendly and confusing, and work or family responsibilities [6,13]. Given that these factors may unequally affect women and men, as well as the various regions in Ghana, understanding how and why these impact the health seeking behavior of each gender and each region warrants more inquiry. It will be important to investigate if indeed, with the availability of ART, male patients, vis-à-vis female patients, are more likely to engage the services of alternative health care outlets. Also, differences between the ten administrative regions in the proportion of persons likely to solicit HIV-related care from the informal sector warrant investigation.

Furthermore, disparities in utilization of ART can be explained by inequities related to access to health service benefits in Ghana. Studies have shown differentials in the distribution of health service benefits across various subgroups in Ghana [55]. For instance, geographical access to health care services has been identified as a key challenge for rural populations in Ghana [55]. Unfortunately, such barriers potentially prevent some eligible HIV patients from having equal and timely access to treatment, thereby further widening the health inequity gap. In this context, promoting equal access to ART means addressing inherent inequities in access to health service benefits in the country. Structures must be put in place to ensure timely access to ART by all eligible HIV patients irrespective of gender, age, location or socio-economic status.

In this study, we reviewed a national dataset to describe the sex and regional distribution of HIV patients receiving ART in Ghana. The limitation, however, is that this dataset is based on routine service provision records that may sometimes be incomplete. Also, since these data do not include other demographic information on patients it is difficult to determine double counting or to identify patients who are no longer receiving the service due to death or loss to follow-up. Another limitation is in using the national proportion of the 15-49 year age group to estimate the regional adult population. It is important to note, however, that the US Census Bureau estimations, the source for these regional estimations, uses the Ghana Demographic Health Survey, a population-based survey which provides good coverage of the general population [56]. The GDHS is also used in calculating population estimations of HIV prevalence 
in Ghana [39,57]. Despite these limitations, it is remarkable to note that our study uses data from different time periods and different regions within the country to show the disproportionally lower use of ART services by males. Also, by using a national dataset we were able to look critically at the outcome of the ART scale-up efforts in the launching years from 2003 to 2010, offering insight into operational realities.

\section{Conclusions}

Considering findings from this study and several others, it is clear that men are underrepresented in the distribution of HIV patients receiving ART in Ghana, and several other African settings. Unfortunately, this has led to increased mortality among the male HIV-population in Africa $[13,45]$. Although explanations for increased mortality among men include men's poor healthcare decisions, service structures need to enhance their capacity to attract and serve males [20]. Policy makers in Ghana and elsewhere need to understand how gender inequality affects both men and women and begin to design gender-based interventions. Barriers against accessing HIV-related care amongst men must be investigated. In addition, HIV- related services, such as HIV testing, can be established within male-dominated spaces, e.g. in locales such as sports arenas or social clubs. By so doing HIV-related care will be brought closer to males. ART scale-up efforts across Africa should pay candid attention to sex and regional disparities if indeed we want to encourage high involvement in HIV-related care by all eligible subgroups.

\section{Abbreviations \\ ART: antiretroviral therapy; PEPFAR: President's Emergency Plan for AIDS Relief; WHO: World Health Organization; NACP: National AIDS/STIs Control Program; GHS: Ghana Health Service.}

\section{Competing interests}

The authors declare that they have no competing interests.

\section{Authors' contributions}

All authors (PDG, RC and AEY) contributed to the conception, analysis and interpretation of data. AEY assisted with acquisition of the dataset. PDG, RC and AEY participated in the writing of the manuscript. All authors read and approved the final manuscript.

\section{Acknowledgements}

We are grateful to Dr Nii A. Addo (Program Manager of NACP) for leading the fight against HIV and AIDS in Ghana; Drs Dornoo and Ayisi-Addo of the NACP, for explanations on aspects of the data. Also to Mr. Ekow Wiah (National Data Manager of the NACP). Manuscript preparation was made possible through funding from the Fogarty International Center at the National Institutes of Health, Grant Number: 1R24TW008814 - 01, as part of the Ghana-Michigan PARTNER program (Postdoctoral And Research Training NEtwoRk).

\section{Author details}

'Department of Social and Behavioral Sciences, School of Public Health, College of Health Sciences, University of Ghana, P. O. Box LG 13, Accra, Ghana. ${ }^{2}$ Department of Health Behavior and Health Education, School of Public Health, University of Michigan, 109 Observatory, 3814, Ann Arbor, MI
48109-2029, USA. ${ }^{3}$ Department of Community Health, University of Ghana Medical School, College of Health Sciences, P. O. Box 4236, Korle-Bu, Accra, Ghana. ${ }^{4}$ National AIDS/STIs Control Program, Ghana Health Service, Korle- Bu, Accra, Ghana.

Received: 9 November 2011 Accepted: 7 May 2012

Published: 16 October 2012

\section{References}

1. Posse M, Baltussen R: Barriers to access to antiretroviral treatment in Mozambique, as perceived by patients and health workers in urban and rural settings. AIDS Patient Care STDs 2009, 3:867-875.

2. Van Damme V, Kober K, Laga M: The real challenges for scaling up ART in sub-Saharan Africa. AIDS 2006, 20:653-656.

3. Ebrahim SH, Anderson JE, Weidle P, Purcell DW: Race/Ethnic disparities in HIV testing and knowledge about treatment for HIV/AIDS: United States 2001. AIDS Patient Care STDs 2004, 18:27-33.

4. Makwiza I, Nyerinda L, Bongololo G, Talumba B, Chimzizi R, Theobald S: Who has access to counseling and testing and anti-retroviral therapy in Malawi-an equity analysis. International Journal for Equity in Health 2009, 8:1-9.

5. Assefa Y, Van Damme W, Marian DH, Kloos H: Toward universal access to HIV counseling and testing and antiretroviral treatment in Ethiopia: Looking beyond HIV testing and ART initiation. AIDS Patient Care STDS 2010, 24:521-525.

6. Mshana GH, Wamoyi J, Busza J, Zaba B, Changalucha J, Kaluvya S, Urassa M: Barriers to assessing antiretroviral therapy in Kisesa, Tanzania: A qualitative study of early rural referrals to the national program. AIDS Patient Care STDs 2006, 20:649-657.

7. Wagner $G$, Ryan $G$, Taylor $S$ : Formative evaluation of antiretroviral therapy scale-up efficiency in sub-Saharan Africa. AIDS Patient Care STDs 2007, 21:871-887.

8. World Health Organization, UNAIDS: Progress on Global Access to HIV Antiretroviral Therapy. A Report on "3 by 5" and Beyond. Geneva: World Health Organization; 2006

9. World Health Organization/UNAIDS: UNAIDS World AIDS Day Report, 2011 [http://www.unaids.org/en/media/unaids/contentassets/documents/ unaidspublication/2011/JC2216_WorldAIDSday_report_2011_en.pdf], (accessed April 2, 2012).

10. Ghana AIDS Commission: Ghana's progress report on the United Nations General Assembly Special Session (UNGASS). Ghana: Declaration of commitment on HIV and AIDS. Ghana AIDS Commission; 2010.

11. Laurent C: Scaling up HIV treatment in resource-limited countries: The challenge of staff shortages. Journal of Public Health Policy 2011, 32:211-218.

12. Gilks CF, Crowley S, Ekpini R, Gove S, Perriens j, Souteyrand Y, Sutherland D, Vitoria M, Guerma T, De Cock K: The WHO public-health approach to antiretroviral treatment against HIV in resource-limited settings. Lancet 2006, 368:505-510

13. Braitstein P, Boulle A, Nash D, Brinkhof MW, Dabis F, Laurent $C$, Schechter M, Tuboi SH, Sprinz E, Miotti P, Hosseinipour M, May M, Egger M, Bangsberg $D R$, Low N: Gender and the use of antiretroviral treatment in resourceconstrained settings: Findings from a multicenter collaboration. J Women's Health 2008, 17:47-55.

14. Muula AS, Ngulube TJ, Siziya S, Makupe CM, Umar E, Prozesky HW, Wiysonge CS, Mataya RH: Gender distribution of adult patients on highly active antiretroviral therapy (HAART) in Southern Africa: a systematic review. BMC Publ Health 2007, 7:1-8.

15. Macintyre $\mathrm{S}$, Hunt $\mathrm{K}$, Sweeting $\mathrm{H}$ : Gender differences in health: are things really as simple as they seem? Soc Sci Med 1996, 42:617-24.

16. Saltonstall R: Healthy bodies, social bodies: men's and women's concepts and practices of health in everyday life. Soc Sci Med 1993, 36:7-14.

17. Courtenay WH: Constructions of masculinity and their influence on men's well-being: a theory of gender and health. Soc Sci Med 2000, 50:1385-1401.

18. Noone JH, Stephens $\mathrm{C}$ : Men, masculine identities and health care utilization. Sociol Health \& III 2008, 30:771-25.

19. UNAIDS, World Health Organization: The HIV/AIDS Pandemic and its gender implications. Women's International Network 2000.

20. Birungi J, Mills E: Can we increase male involvement in AIDS treatment? Lancet 2010, 376:1302 
21. Snow R: The social body: Gender and the burden of disease. In Gender Equity in Health. The Shifting Frontiers of Evidence and Action. Edited by Sen G, Ostlin P. New York: Routledge Taylor and Francis Group; 2010:47-69.

22. Braga $P$, Cardoso MA, Segurado AC: Gender differences in survival in an HIV/AIDS cohort from Sao Paulo, Brazil. AIDS Patient Care STDs 2007, 21:321-328.

23. Quinn TC, Overbaugh J: HIV/AIDS in women: An expanding epidemic. Science 2005, 308:1582-1583.

24. Baghdadi G: Gender and medicines: An international public health perspective. J Women's Health 2005, 14:82-86.

25. Remien RH, Chowdhury J, Mokhbat J, Soliman C, Adawi ME, El-Sadr W: Gender and Care: Access to HIV Testing, Care and Treatment. J Acquir Immune Defic Syndr 2009, 51:S106-S110.

26. Schofield T, Connell RW, Walker L, Wood JF, Butland DL: Understanding men's health and illness: A gender relations approach to policy, research and practice. J Am Coll Health 2000, 48:247-256.

27. Greig A, Kimmel M, Lang J: Gender in Development Monograph Series 10. New York: UNDP; 2000

28. Wyrod R: Masculinity and the persistence of AIDS stigma. Cult Health Sex 2011, 13:443-456.

29. Robertson S: Men managing health. Men's Health Journal 2003, 2:111-13.

30. Kloos H, Assefa Y, Adugna A, Mulatu MS, Marian DH, Marian DH: Utilization of antiretroviral treatment in Ethiopia between February and December 2006: spatial, temporal and demographic patterns. Int J Health Geogr 2007, 6:1-12

31. Wouters E, Heunis C, Ponnet K, Van Loon F, Booysen FR, Rensburg VD, Meulemans $\mathrm{H}$ : Who is accessing public-sector anti-retroviral treatment in the Free State, South Africa? An exploratory study of the first three years of programme implementation. BMC Publ Health 2010, 10:387.

32. Makombe S, Libamba E, Mhango E, Teck OA, Aberle-Grasse J, Hochgesanga $M$, Schouten EJ, Harries AD: Who is accessing antiretroviral therapy during national scale-up in Malawi? Trans R Soc Trop Med Hyg 2006, 100:975-979.

33. Ghana Health Service, World Health Organization, National AIDS/STIs Control Program: National HIV prevalence and AIDS estimates report, 20102015. Accra: NACP/GHS/MOH; 2011

34. National AIDS/STIs Control Program, Ghana Health Service, Ministry of Health: National ART Guidelines. Accra: NACP/GHS/MOH; 2010

35. Ampofo WK: Current status of HIV/AIDS treatment, care and support services in Ghana. Ghana Med J 2009, 43:142-143.

36. World Health Organization/UNAIDS: Global Report: UNAIDS report on the global AIDS epidemic. AA: AA; 2010. http://www.unaids.org/globalreport/ Global_report.htm. (accessed November 9, 2011).

37. Wolff $\bar{M} J$, Beltran CJ, Vasquez P, Ayala Mx, Valenzuela M, Berrios G, Arrendondo A: The Chilean AIDS cohort. A model for evaluating the impact of an expanded access program to antiretroviral therapy in a middle-income country - Organization and preliminary results. J Aquir Immune Defic Syndr 2005, 40:551-557.

38. Ghana Health Service: Annual Report. Accra: NACP: 2011

39. National AIDS/STIs Control Program: HIV Sentinel Survey and National HIV Prevalence, AIDS Estimates Report (2011). Accra: NACP/GHS/MOH; 2011.

40. US Census Bureau: International Programs [database online]: Ghana Demographic Indicators 2010. http://www.census.gov/population/ international/data/idb/country.php (accessed November 15, 2011).

41. Ghana Statistical Service: 2010 Population and housing census provisional results. GSS Ghana; 2011

42. Ritzenthaler R: Delivering antiretroviral therapy in resource-constrained settings: Lessons from Ghana, Kenya and Rwanda. Virginia: FHl; 2005.

43. World Health Organization: Global burden of disease: 2004 update. Geneva: WHO; 2008.

44. Ghana Statistical Service (GSS), Noguchi Memorial Institute for Medical Research (NMIMR), ORC Macro: Ghana Demographic and Health Survey 2003. Maryland: GSS/NMIMR/ORC Macro; 2004

45. May M, Boulle A, Phiri S, Messou E, Myer L, Wood R, Keiser O, Sterne JAC, Dabis F, Egger M: Prognosis with HIV-1 infection starting antiretroviral therapy in sub-Saharan Africa: a collaborative analysis of scale-up programmes. Lancet 2010, 376:449-457.

46. Torpey K, Lartey M, Amenyah R, Addo NA, Obeng-Baah J, Rahman Y, Suzuki C, Mukadi YD, Colebunders R: Initiating antiretroviral treatment in a resource-constrained setting: does clinical staging effectively identify patients in need? Int J STD AIDS 2009, 20:395-398.
47. Snow R, Madalane M, Poulsen M: Are men testing? Sex differentials in HIV testing in Mpumalanga Province, South Africa. AIDS Care 2010, 22:1060-1065.

48. Ghana Statistical Service (GSS), Ghana Health Service (GHS), ICF Macro: Ghana Demographic and Health Survey, 2008. Maryland: GSS/GHS/ICF Macro; 2009

49. Yawson AE, Dako-Gyeke P, Snow RC: Sex differences in HIV testing in Ghana, and policy implications. AIDS CARE 2012, in press.

50. Wetherell M, Edley N: Negotiating hegemonic masculinity: imaginary positions and psycho-discursive practices. Fem Psychol 1999, 9:335-56.

51. Jefferson T: Subordinating hegemonic masculinity. Theor Crim 2002, 6:63-88.

52. Federal Democratic Republic of Ethiopia, Federal HIV/AIDS Prevention and Control Office: Report on progress towards implementation of the UN Declaration of Commitment on HIV/AIDS 2010, June 2011. 2011 http://www. unaids.org/en/dataanalysis/monitoringcountryprogress/ 2010progressreportssubmittedbycountries/ ethiopia_2010_country_progress_report_en.pdf (accessed October 16, 2011)

53. Stringer JSA, Zulu I, Levy J, Stringer EM, Mwango A, Chi BH, Mtonga V, Reid S, Cantrell RA, Bulterys M, Saag MS, Marlink RG, Mwinga A, Ellerbrock TV, Sinkala M: Rapid scale-up of antiretroviral therapy at primary care sites in Zambia feasibility and early outcomes. JAMA 2006, 296:782-793.

54. Awusabo-Asare K, Anarfi JK: Health-seeking behavior of persons with HIV/ AIDS in Ghana. Health Transit Rev 1997, 7:243-254.

55. Akazili J, Garshong B, Aikins M, Gyapong J, McIntyre D: Progressivity of health care financing and incidence of service benefits in Ghana. Health Policy Plann 2012, 27:113-i22.

56. Working Group on Global HIV/AIDS and STI surveillance: Guidelines for measuring national HIV prevalence in population-based surveys. 2005. http:// www.unaids.org/en/media/unaids/contentassets/dataimport/pub/manual/ 2005/20050101_gs_guidemeasuringpopulation_en.pdf (accessed September 15, 2011).

57. National AIDS/STIs Control Program/Ghana Health Services: National HIV prevalence and AIDS estimates report, 2011-2015. Accra: NACP/GHS; 2012.

doi:10.1186/1475-9276-11-62

Cite this article as: Dako-Gyeke et al:: Who is utilizing anti-retroviral therapy in Ghana: An analysis of ART service utilization. International Journal for Equity in Health 2012 11:62.

\section{Submit your next manuscript to BioMed Central and take full advantage of:}

- Convenient online submission

- Thorough peer review

- No space constraints or color figure charges

- Immediate publication on acceptance

- Inclusion in PubMed, CAS, Scopus and Google Scholar

- Research which is freely available for redistribution 